\title{
Assessment of offshore shrimp stocks of Bangladesh based on commercial shrimp trawl logbook data
}

\author{
SUMAN BARUA, ARNI MAGNUSSON* AND NASIRUDDIN MD HUMAYUN \\ Marine Fisheries Office, Department of Fisheries, CGO Building 1, Agrabad, Chittagong, Bangladesh \\ "ICES Secretariat, H. C. Andersens Boulevard 44-46, 1553 Copenhagen, Denmark
}

\begin{abstract}
This study presents the results of analytical assessment of offshore shrimp stock in Bangladesh marine waters. A time series of annual catch per unit effort (CPUE) was derived from commercial logbook data during the period from 1986 to 2016 and used as a turning series for a Schaefer biomass model. The current stock size and annual harvest rate were estimated to be around $20300 \mathrm{t}$ and $20 \%$ respectively, with the stock size increasing in the last ten years. The estimated maximum sustainable yield (MSY) reference points with $95 \%$ confidence intervals are optimal biomass $B_{\mathrm{MSY}}=15800 \mathrm{t}(11300-22000 \mathrm{t})$ and optimal harvest rate $u_{\mathrm{MSY}}=30 \%(21-42 \%)$. The average annual catch was $4650 \mathrm{t}$, close to the estimated MSY of $4710 \mathrm{t}(4570-4860 \mathrm{t})$. Overall, the stock is estimated to be in a good state and the data show that CPUE in recent years is slightly above the long-term average. The assessment results are subject to considerable uncertainty, reflected in wide confidence intervals around the estimated stock status. Moreover, the simple assessment model has restrictive assumptions that may not capture the underlying dynamics of the Bangladesh shrimp fishery, a multispecies tropical fishery with changes in the fleet composition and fishing technology. Nevertheless, the model fits well to the CPUE data and the assessment is a valuable basis for giving short-term and long-term management advice.
\end{abstract}

Keywords: Bangladesh, Biomass model, Offshore shrimp stock, Stock assessment, Trawl logbook

\section{Introduction}

The fisheries sector of Bangladesh is important as a source of food, livelihood and foreign exchange earnings. The diverse fisheries resources are divided into three groups viz., inland capture, inland culture and marine capture, with marine fisheries generating about $16 \%$ of the country's total fish production in 2015-16. Of this, marine shrimp accounts for $8 \%$ of total marine fisheries production and industrial shrimp trawl accounts for $6 \%$ of total marine shrimp production (DoF, 2017).

A number of pilot surveys were conducted in the beginning of the 1970s to assess the stocks of fish and shrimp in the Bay of Bengal. The surveys were initiated by FAO, at the same time as a demersal trawling fleet was developing and a number of stock assessments were carried out by international scientists in association with local experts. In the earliest assessment, West (1973) estimated a virgin stock of 6800-11400 $\mathrm{t}$ of shrimp biomass using the survey data collected during the period 1968-1971. Rashid (1983) calculated the standing stock of shrimp as $8400 \mathrm{t}$ based on data from the Mitsui Tayo survey in 1976-77. A few years later, a survey was conducted using swept area method during 1981-83, which reported a standing stock of 3000-3600 t (White and Khan, 1985).
Industrial fishing through private ownership developed over the years (Rahman et al., 1995) and by 2015-16 there were 204 industrial fishing vessels operating within the EEZ in waters of over $40 \mathrm{~m}$ depth, of which 31 were shrimping vessels (DoF, 2017). The shrimp catch is commercially categorised into 'tiger', 'white', 'brown' and 'flower'. The species caught are Penaeus monodon (Fabricius, 1798), Penaeus semisulcatus (De Hann, 1844), Penaeus japonicus (Spence Bate, 1888), Penaeus indicus (H. Milne Edwards, 1837), Penaeus merguiensis (De Man, 1888), Metapenaeus monoceros (Fabricius 1798), Metapenaeus spinulatus (Kubo 1949) and Metapenaeus brevicornis (H. Milne Edwards 1837) (Rao, 1987; Uddin et al., 2012). Less commercially important species include Parapenaeopsis sculptilis (Heller, 1862), Parapenaeopsis stylifera (H. Milne Edwards, 1837) and Acetes indicus H. Milne Edwards, 1830. Brown shrimp is usually the highest in quantity forming around $60 \%$ of the annual shrimp catch (Uddin et al., 2012).

Maximum sustainable yield (MSY) is usually used to establish a target harvest rate (Hilborn and Walters, 1992; Quinn and Deriso, 1999) in fisheries. When age or size composition data are not available, MSY reference points can be estimated using simple biomass models, such as the Schaefer (1954) and Fox (1970) models, where the effects of recruitment, growth and mortality are combined 
into a single production function. The two models are similar, but make slightly different biological assumptions about the shape of the surplus production as a function of biomass.

Standard biomass models like the Schaefer and Fox models have the following assumptions: (a) there are no species interactions, (b) the intrinsic growth rate is independent of age composition, (c) no environmental factors affect the population, (d) the intrinsic growth rate responds instantaneously to changes in population biomass with no time delays, (e) the catchability coefficient is constant, (f) there is a single stock unit, ( $g$ ) fishing and natural mortality take place simultaneously, (h) no changes in gear or vessel efficiency have taken place and (i) catch and effort statistics are accurate (Musick and Bonfil, 2004). Although many of the assumptions are not very realistic, the model can be used to describe the main dynamics and historical trends for a given fishery and to form the analytical basis of advice for fisheries management.

Biomass models have been used in the past to evaluate MSY reference points for the Bangladesh shrimp fisheries. Khan and Hoque (2000) analysed the penaeid shrimp fishery data in Bangladesh marine waters and estimated the MSY as $4140 \mathrm{t}$ using a Schaefer model and $4330 \mathrm{t}$ using a Fox model. Kar and Chakraborty (2011) applied a Schaefer model together with a conventional economic model on Bangladesh shrimp fishery data and estimated the MSY as 3790 t. Ray and Khan (2003) applied related methods, the Verhulst equation and Pauly's model to data from Bangladesh shrimp fishery from 1981 to 1998 and estimated $r$ as 1.33 .

In this study, we attempted stock assessment of the offshore shrimp stocks of Bangladesh marine waters using latest analytical tools. The results are interpreted in the context of formulation of sustainable management measures in comparison with the findings of previous studies.

\section{Materials and methods}

\section{Data sources}

The time series data (catch and effort) of commercial shrimp stocks in Bangladesh marine waters from 1986 to 2016 (Fig. 1) were taken from logbook data sheets of the Marine Fisheries Office (Table 1). The prevalence of under-reporting of shrimp catch is considered to be low, since the majority of the catch of major shrimp species is exported. The catch data were converted from headless weight to total weight using the conversion factor of 0.63 for tiger shrimp, 0.66 for brown shrimp, 0.68 for white shrimp, and 0.65 for others. Shrimp trawlers engaged in fishing within the EEZ of Bangladesh beyond $40 \mathrm{~m}$ depth

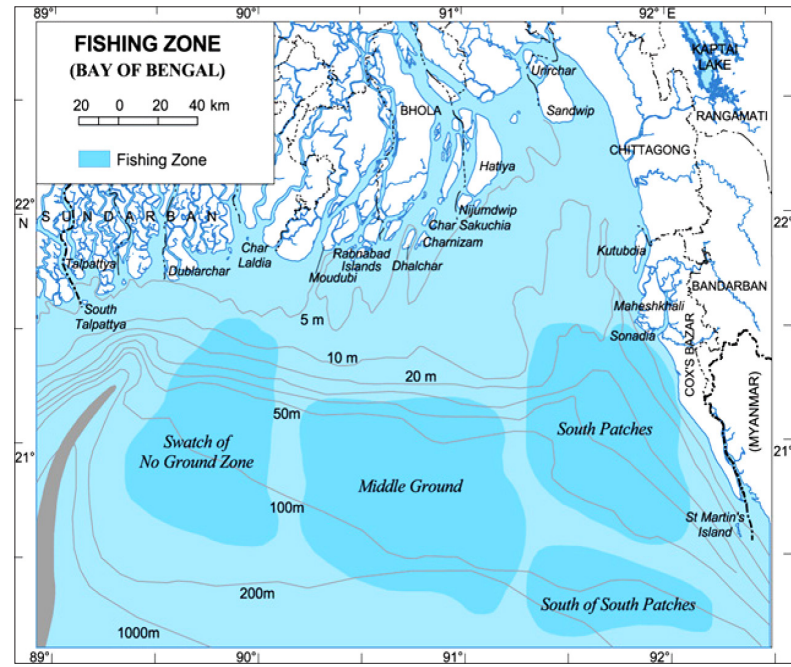

Fig. 1. Map showing the commercial fishing zone in Bangladesh marine waters

Table 1. Catch and effort data for the offshore shrimp fishery of industrial trawlers (Source: Marine Fisheries Office report).

\begin{tabular}{|c|c|c|c|}
\hline Year & Time (days) & Catch (t) & CPUE $\left(\mathrm{t}\right.$ day $\left.^{-1}\right)$ \\
\hline 1986 & 6429 & 6372 & 0.9911 \\
\hline 1987 & 6642 & 5137 & 0.7734 \\
\hline 1988 & 7806 & 7361 & 0.9430 \\
\hline 1989 & 7394 & 4790 & 0.6478 \\
\hline 1990 & 5658 & 5568 & 0.9841 \\
\hline 1991 & 5529 & 4004 & 0.7242 \\
\hline 1992 & 6588 & 5953 & 0.9036 \\
\hline 1993 & 7113 & 5255 & 0.7388 \\
\hline 1994 & 6691 & 3651 & 0.5457 \\
\hline 1995 & 6502 & 5411 & 0.8322 \\
\hline 1996 & 6914 & 5350 & 0.7738 \\
\hline 1997 & 7044 & 3691 & 0.5240 \\
\hline 1998 & 7645 & 5643 & 0.7381 \\
\hline 1999 & 7152 & 4428 & 0.6191 \\
\hline 2000 & 7289 & 4808 & 0.6596 \\
\hline 2001 & 6935 & 4783 & 0.6897 \\
\hline 2002 & 7069 & 3736 & 0.5285 \\
\hline 2003 & 7442 & 4655 & 0.6255 \\
\hline 2004 & 7866 & 4977 & 0.6327 \\
\hline 2005 & 7466 & 5138 & 0.6882 \\
\hline 2006 & 5919 & 3260 & 0.5508 \\
\hline 2007 & 5969 & 3932 & 0.6587 \\
\hline 2008 & 5956 & 4386 & 0.7364 \\
\hline 2009 & 4581 & 3752 & 0.8190 \\
\hline 2010 & 4718 & 4085 & 0.8658 \\
\hline 2011 & 4116 & 3244 & 0.7881 \\
\hline 2012 & 4436 & 4312 & 0.9720 \\
\hline 2013 & 4935 & 5133 & 1.0401 \\
\hline 2014 & 4543 & 3565 & 0.7847 \\
\hline 2015 & 4703 & 3527 & 0.7499 \\
\hline 2016 & 4635 & 4090 & 0.8824 \\
\hline
\end{tabular}


contour usually have $150-250$ t gross tonnage capacity with main engine power of 500-900 BHP. The maximum number of days of fishing per trip is 30 days. Trawlers typically complete 5-6 hauls per day, each for a period of 3-4 h. The fishing days and number of hauls vary depending on weather and sea worthiness of the vessel itself (Uddin et al., 2012). The catch is expressed in metric tons ( $\mathrm{t}$ ) and effort is measured as the total number of fishing days of all vessels.

\section{Biomass model}

For this study, a Schaefer (1954) model was used to model the shrimp fishery,

$$
\mathrm{B}_{\mathrm{t}+1}=\mathrm{B}_{\mathrm{t}}+\mathrm{rB}_{\mathrm{t}}\left[1-\frac{\mathrm{Bt}}{\mathrm{K}}\right]-\mathrm{C}_{\mathrm{t}}
$$

where, $B=$ biomass, $t=$ time (year), $K=$ carrying capacity, $C=$ catch and $r=$ intrinsic population growth rate. The biomass in the first year is modelled as $B_{\text {init }}=$ $a K$, where the fraction $a$ is an estimated model parameter, describing initial population size as a fraction of the carrying capacity. As indicated by the $t$ subscripts, the population size can be evaluated one year further than the last year of catch data. Harvest rate is defined as the catch as a fraction of the biomass in a given year, $u_{t}=C_{t} / B_{t}$. The MSY-based reference points for the Schaefer model are:

$$
\begin{aligned}
& u_{\mathrm{MSY}}=0.5 \mathrm{r} \\
& B_{\mathrm{MSY}}=0.5 \mathrm{~K} \\
& \mathrm{MSY}=0.25 r \mathrm{~K}
\end{aligned}
$$

where $B_{\mathrm{MSY}}$ is the population size where the surplus production maximises, $u_{\mathrm{MSY}}$ is the optimal harvest rate, and MSY is the maximum sustainable yield (Polacheck et al., 1993)

\section{Model fitting procedure}

The model is tuned to the biomass index time series, where the fitted indices are calculated as: $I_{t}=q_{t}$ (Richards and Schnute, 1986), where $I$ is the biomass index and $q$ is the catchability coefficient, serving as a simple scaling factor. The biomass index can either be from the commercial fishery or based on survey abundance information (Barua et al., 2018).

The model parameters were estimated by iteratively searching for parameter values that minimise the objective function, which is the negative log likelihood of the model fit,

$$
-\log L=0.5 n \log (2 \pi)+n \log \sigma+R S S / 2 \sigma^{2}
$$

where $L=$ likelihood, $n=$ number of biomass indices, $\sigma=$ estimated variability of biomass indices, and $R S S=$ residual sum of squared $\log$ residuals,
$\Sigma\left(\log \hat{\mathrm{I}}_{\mathrm{t}}-\log \mathrm{I}_{\mathrm{t}}\right)^{2}$ Thus, a total of 5 model parameters were estimated: $r, K, a, q$ and $\sigma$.

\section{Statistical software}

To ensure that the best parameter estimates were found, the parameter estimation was replicated in three different software platforms: Microsoft Excel Solver, AD Model Builder, ADMB (Fournier et al., 2012) and Template Model Builder, TMB (Kristensen et al., 2016). The latter two are based on automatic differentiation, which has been shown to be an effective technique when fitting nonlinear models (Bolker et al., 2013). The ADMBIDE environment (Magnusson, 2009) was used to develop and run the Schaefer model in AD Model Builder.

\section{Evaluating uncertainty}

The delta method (Seber, 1973) was used to construct confidence intervals around the estimated reference points. It is a built-in method in AD Model Builder and Template Model Builder, utilising exact partial derivatives, and is a recommended method to evaluate uncertainty about reference points in fisheries stock assessment (Magnusson et al., 2013).

\section{Results}

Model fit and estimates

The model converged and resulted in similar parameter estimates in all three software platforms, Excel, $\mathrm{ADMB}$ and $\mathrm{TMB}$ and the confidence intervals from $\mathrm{ADMB}$ and $\mathrm{TMB}$ were similar between the two platforms. Overall, the model fits the biomass index quite well, capturing the main temporal trends in the observed data (Fig. 2).

Point estimates of parameters and key quantities are shown in Table 2, along with the $95 \%$ confidence intervals. The $r$ and $K$ parameters are estimated as 0.597 and 31544 , respectively. The estimated harvest rate in 2016 is $20.4 \%$,

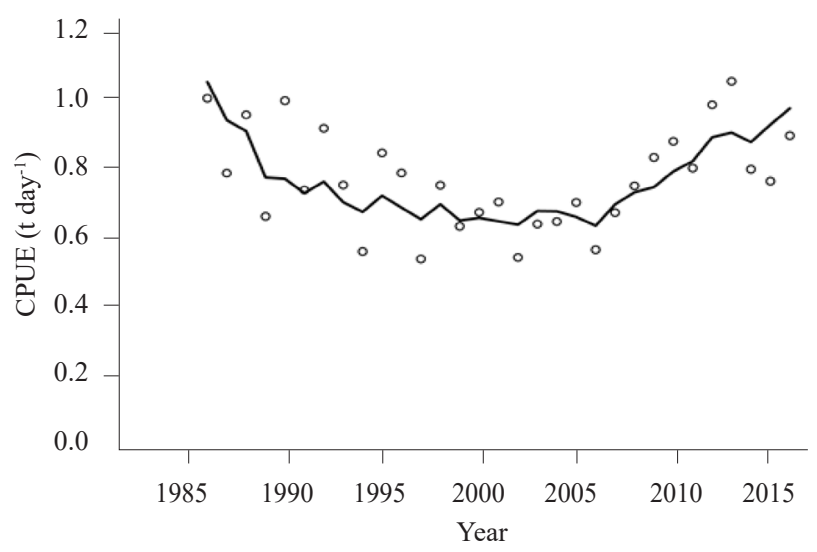

Fig. 2. Observed (circles) and fitted (line) biomass indices 
Table 2. Point estimates and 95\% confidence intervals of estimated parameters, biomass in 2017 and reference points.

\begin{tabular}{lll}
\hline Quantity & Estimate & $95 \%$ CI \\
\hline$r$ & 0.597 & $0.426-0.837$ \\
$K$ & 31544 & $22605-44018$ \\
$\mathrm{a}$ & 0.685 & $0.511-0.918$ \\
$q$ & $4.81 \times 10^{-5}$ & $3.46 \times 10^{-5}-6.68 \times 10^{-5}$ \\
$\sigma$ & 0.124 & $0.097-0.159$ \\
\hline$u_{2016}$ & 0.204 & $0.159-0.263$ \\
$B_{2017}$ & 20286 & $15706-26201$ \\
\hline$u M S Y$ & 0.298 & $0.213-0.418$ \\
$B_{M S Y}$ & 15772 & $11302-22009$ \\
$M S Y$ & 4709 & $4565-4858$ \\
\hline
\end{tabular}

lower than $u_{\mathrm{MSY}}$ at $29.9 \%$, while the estimated biomass in 2017 is $20286 \mathrm{t}$, higher than $B_{\mathrm{MSY}}$ at $15772 \mathrm{t}$. The average annual catch in 1986-2016 is $4645 \mathrm{t}$, close to the estimated MSY of $4709 \mathrm{t}$.

\section{Estimates of historical stock size and harvest rate}

The biomass is estimated as $2160 \mathrm{t}$ in 1986 , then gradually declining over the next two decades to $12910 \mathrm{t}$ in 2006, increasing again in recent years to $20286 \mathrm{t}$ in 2017 (Fig. 3). Catches were in the range from 3244 to $7361 \mathrm{t}$, with the highest catch in 1988 and the lowest in 2011. The harvest rate is estimated to have fluctuated between $18 \%$ and $40 \%$ in the years 1986-2016, with lower harvest rates (18\% to $29 \%$ ) in the last ten years (Fig. 4).

\section{Discussion}

Some of the key estimates resulting from the analysis of the population dynamics of the Bangladesh offshore shrimp fishery are : intrinsic growth rate $(r)=0.597$ and carrying capacity $(K)=31544 \mathrm{t}$, corresponding to optimal

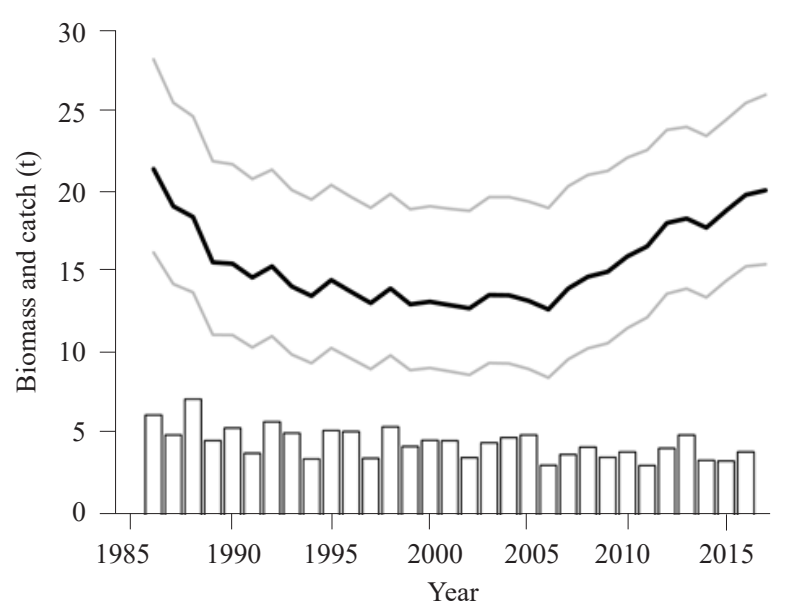

Fig. 3. Estimates of stock biomass (black line) with $95 \%$ confidence bands (gray lines), along with catch (bars)

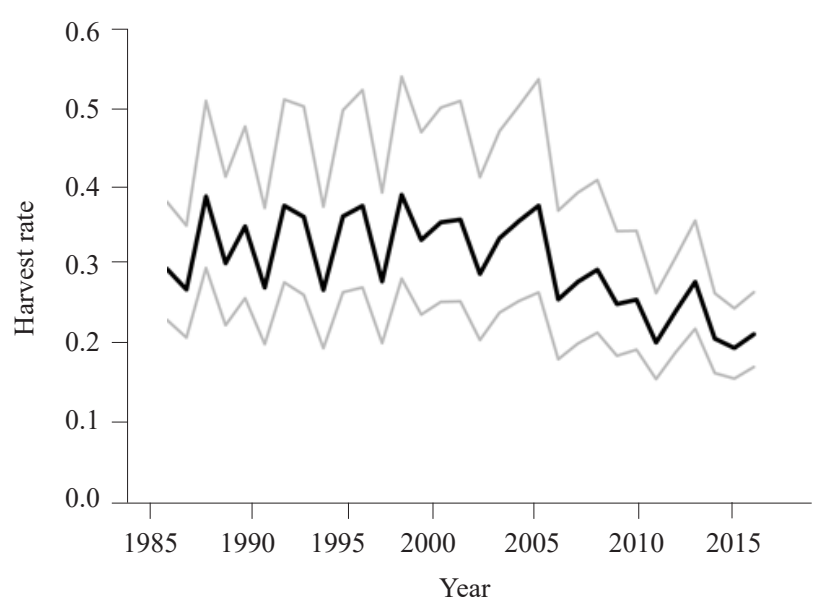

Fig. 4. Estimates of harvest rate with $95 \%$ confidence bands

harvest rate $\left(u_{\mathrm{MSY}}\right)=30 \%$, optimal stock size $\left(B_{\mathrm{MSY}}\right)=$ $15772 \mathrm{t}$ and maximum sustainable yield $(\mathrm{MSY})=4709 \mathrm{t}$.

Compared to earlier studies, the MSY estimate of $4709 \mathrm{t}$ is higher than those reported by Khan and Hoque (2000), who estimated MSY as $4140 \mathrm{t}$ or $4330 \mathrm{t}$, and also higher than the $3790 \mathrm{t}$ estimated by Kar and Chakraborty (2011). The present analysis incorporates more data and the $95 \%$ confidence interval is $4565-4858 \mathrm{t}$, evaluated using the delta method. The estimated $r$ of $0.597(0.426-0.837)$ in the current study is considerably lower than the 1.33 estimate from Ray and Khan (2003). The estimated value of $r$ has a direct relationship with the estimated optimal harvest rate, in the context of a potential long-term target reference point for fisheries management. Finally, the estimated carrying capacity of $K=31544 \mathrm{t}$ $(22605-44018 \mathrm{t})$ is a bit higher than the early survey estimate of a virgin stock of 6800-11400 t by West (1973) and the $8400 \mathrm{t}$ estimated from the 1976-1977 survey (Rashid,1983). The current estimates are likely to be more accurate than those from the earlier analyses, which tended to focus on equilibrium dynamics rather than the state of the fishery and looked at less complete datasets from the Bangladesh offshore shrimp fishery. The previous studies, however may indicate, in which direction the current estimates are likely to be biased.

If the biomass estimate in 2017 is multiplied by the estimated optimal harvest rate of $30 \%$, the resulting catch advice could be interpreted as around $6060 \mathrm{t}$. This amount is higher than the most recent catch in the dataset, of around $4090 \mathrm{t}$ in 2016 . However, it should also be considered that there are other important sources of information about the status of the offshore shrimp fishery, beyond the catch and effort dataset used here such as, differences in catch rates between areas; changes in the geographical distribution of the stock and/or fleet; changes in the fleet composition; 
and other aspects that are not easily included in a standard analytical biomass model.

Effort management policies have been used for this stock in the past. For example, in 2003, the authorities imposed restrictions on shrimp trawling, by not replacing old shrimp trawlers by new ones (MoFL, 2003). This resulted in decreased fishing pressure in the following years. Later, a policy of mandatory conversion of ground fish trawlers to mid-water trawlers to limit the fishing impacts on the sea floor and benthic habitat further decreased the fishing pressure on the shrimp.

Overall, there are indications that the stock is in a relatively good state, based on recent catch and effort trends in the observed data, as well as model estimates. The most recent harvest rates are estimated below the optimal, in contrast to the period from 1986 to 2008 when the average harvest rates were estimated to be higher than optimal. The results generated from the present study can be used for suggesting management measures, augmenting other sources of information of the offshore shrimp stock.

\section{Acknowledgements}

We would like to thank the two anonymous referees for helpful comments on an earlier draft of this paper. This research was made possible by the Fisheries Training Programme of the United Nations University.

\section{References}

Barua, S., Thordarson, G. and Jonsdottir, I. G. 2018. Comparison of catch and survey data for assessing northern shrimp (Pandalus borealis) from Arnarfjordur (NW-Iceland) using a stock production model. Turk. J. Fish. Aquat. Sci., 18: 359-366. DOI: 10.4194/1303-2712-v18_3_01

Bolker, B. M., Gardner, B., Maunder, M., Berg, C. W., Brooks, M., Comita, L., Crone, E., Cubaynes, S., Davies, T., Valpine, P. and Ford, J. 2013. Strategies for fitting nonlinear ecological models in R, AD Model Builder, and BUGS. Methods Eco. Evol., 4: 501-512.

DoF 2017. National fish week 2017. Compendium (in Bangla). Department of Fisheries, Ministry of Fisheries and Livestock, Bangladesh, $160 \mathrm{pp}$.

Fournier, D. A., Skaug, H. J., Ancheta, J., Ianelli, J., Magnusson, A., Maunder, M., Nielsen, A. and Sibert, J. 2012. AD Model Builder: using automatic differentiation for statistical inference of highly parameterised complex nonlinear models. Optim. Methods Softw., 27: 233-249. ISSN 1055-6788.

Fox, W. W. 1970. An exponential surplus yield model for optimising exploited fish populations. Trans Am. Fish. Soc., 99: 80-88.
Hilborn, R. and Walters, C. J. 1992. Quantitative fisheries stock assessment, choices, dynamics and uncertainty. Chapman and Hall, New York.

Kar, T. K. and Chakraborty, K. 2011. A bioeconomic assessment of the Bangladesh shrimp fishery. World J. Model. Simul., 7: 58-69.

Khan, M. S. and Hoque, M. S. 2000. Bioeconomics modelling: Bangladesh shrimp fishery. Proceedings of the International Seminar, Malaysia.

Kristensen, K., Nielsen, A., Berg, C. W., Skaug, H. and Bell, B. 2015. TMB: Automatic differentiation and laplace approximation. J. Stat. Softw., 70(5): 1-21.

Magnusson, A. 2009. ADMB-IDE: Easy and efficient user interface. ADMB Foundation Newsletter, 1(3): 1-2.

Magnusson, A., Punt, A. E. and Hilborn, R. 2013. Measuring uncertainty in fisheries stock assessment: the delta method, bootstrap and MCMC. Fish Fish., 14(3): 325-342.

MoFL 2003. Circular No. 160, Ministry of Fisheries and Livestock, Bangladesh Secretariat, Dhaka.

Musick, J. A. and Bonfil. R. 2004. Elasmobranch fisheries management techniques. Asia-Pacific Economic Cooperation (APEC), Fisheries Working Group, Singapore, p. 133-164.

Polacheck, T., Hilborn, R. and Punt, A. 1993. Fitting surplus production models: comparing methods and measuring uncertainty. Can. J. Fish. Aquat. Sci., 50: 597-607.

Quinn, T. J. and Deriso, R. B. 1999. Quantitative fish dynamics, Oxford University Press, N. Y., USA.

Rahman, A. K. A., Khan, M. G., Chowdhury, Z. A. and Hossain, M. M. 1995. Economically important marine fishes and shell fishes of Bangladesh. Department of Fisheries. Matshya Bhaban, Dhaka, 53 pp.

Rao, G. S. 1987. A preliminary study on the prawn fishery of big trawlers along the north-east coast of India. Indian $J$. Fish., 34(3): 312-328.

Rashid, M. H., 1983. Mitsui Taiyo shrimp survey 1976-77 by the survey research vessels M. V. Santa Monica and M. V. Orion 8 in the marine waters of Bangladesh, Mar. Fish. Bull., 2: 1-23.

Ray, A. K. and Khan, M. S. U. 2003. Estimating some parameters of trawl shrimp fishery in Bangladesh. Indian J. Fish., 50: 251-257.

Richards, L. J. and Schnute, J. T. 1986. An experimental and statistical approach to the question: is CPUE an index of abundance? Can. J. Fish. Aquat. Sci., 43: 1214-1227.

Schaefer, M. B. 1954. Some aspects of the dynamics of populations important to the management of the commercial marine fisheries, IATTC Bull., 1: 27-56. 
Seber, G. A. F. 1973. Estimation of animal abundance and related parameters, Griffin, London, UK.

Uddin, M. S., Karim, E., Hasan, S. J., Barua, S. and Humayun, N. M. 2012. Catch composition of marine shrimp species in Bangladesh. Bangladesh Res. Publ. J., 7: 91-98.

West, W. Q. B. 1973. Fishery resources of the upper Bay of Bengal. Indian Ocean Programme, Indian Ocean
Fisheries Commission, IOFC/DEV/73/28, FAO, Rome, $44 \mathrm{pp}$.

White, T. F. and Khan, M. G. 1985. The marine resources of Bangladesh and their potential for commercial development. Key note paper. Proceedings of the National Seminar on Fisheries Development in Bangladesh, 1-4. January 1985, Dhaka, Bangladesh, p. 1-4. 